Check for updates

Cite this: RSC Adv., 2021, 11, 32837

Received 14th August 2021

Accepted 29th September 2021

DOI: 10.1039/d1ra06150j

rsc.li/rsc-advances

\section{One-pot synthesis, structural analysis, and oxidation applications of a series of diaryltellurium dicarboxylates $\uparrow$}

\author{
Yuga Shibuya, Anna Toyoda, Shiori Ohmura, Go Higashikawa \\ and Shinichi Koguchi (iD *
}

\begin{abstract}
This paper presents a concise and efficient one-pot synthesis of a variety of functionalized diaryltellurium dicarboxylates. The method is based on a mild photosensitized oxygenation of cheap and readily available carboxylic acids. The molecular structures of the diaryltellurium dicarboxylates were determined unambiguously using single-crystal X-ray diffraction analysis. The thus obtained diaryltellurium dicarboxylates were used to study the oxidation of benzoin derivatives.
\end{abstract}

Recently we have taken interest in the synthesis of organotellurium compounds and the study of their behavior in organic reactions. Specifically, we have reported on the synthesis of organotellurium compounds as well as the oxidation of organic compounds using organotellurium compounds such as telluroxides. ${ }^{1-4}$

We have been interested in extending our methodology to telluroxide derivatives such as diaryltellurium dicarboxylates. Although a method for the synthesis of related diallyl tellurium dicarboxylates has already been reported, it is a complicated reaction that requires very precise reaction conditions. Moreover, there are few reports on the detailed crystallographic characterization of diallyl tellurium dicarboxylates.

So far, the main method for the synthesis of diallyl tellurium dicarboxylates has been to react a diallyl tellurium or a diallyl tellurium derivative with a hypervalent iodine reagent., ${ }^{5,6}$ This method requires hypervalent reagents that are expensive and potentially explosive. Chandrasekhar et al. have reported the synthesis of diallyl tellurium dicarboxylates using diallyl telluroxides and carboxylic acids. However, this method requires the conversion of a diallyl tellurium to a diallyl telluroxide. ${ }^{7}$ It is generally known that the oxidation of a diallyl tellurium to a diallyl telluroxide using peroxides such as $\mathrm{NaIO}_{4}$ carries the risk of explosion. Chandrasekhar et al. also succeeded in synthesizing tellurium ferrocene carboxylates using this same synthetic method. ${ }^{8}$ Furthermore, there is a report on a similar synthetic method for the generation of macrocyclic multi-

Department of Chemistry, Tokai University, 4-1-1 Kitakaname, Hiratsuka-shi, Kanagawa, 259-1292, Japan. E-mail: koguchi@tokai-u.jp

$\dagger$ Electronic supplementary information (ESI) available. CCDC 2097118 (1a), 2097119 (1b), 2097120 (1c), 2097121 (1d), 2097122 (2a), 2097123 (2b) and 2097124 (6a). For ESI and crystallographic data in CIF or other electronic format see DOI: 10.1039/d1ra06150j telluranes using telluronium salts prepared from telluroxides and triflic anhydride. ${ }^{9}$

In this study, we demonstrate a simple and safe method for the synthesis of diaryltellurium dicarboxylates using inexpensive carboxylic acids and air as the source of oxygen. In addition, the molecular structures of the diaryltellurium dicarboxylates in the solid state were determined unambiguously via a singlecrystal X-ray diffraction analysis.

Table 1 Optimisation of the reaction conditions ${ }^{a}$

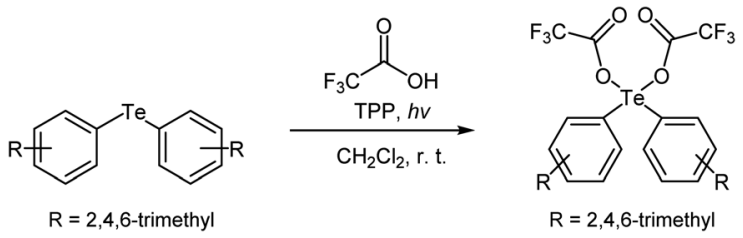

\begin{tabular}{|c|c|c|c|c|}
\hline Entry & Sensitizer $^{b}$ & Time (h) & Conditions & Yield $^{c}(\%$ \\
\hline 1 & Fullerene-C ${ }_{60}(1 \mathrm{~mol} \%)$ & 1.5 & Air & 97 \\
\hline 2 & Fullerene- $\mathrm{C}_{60}(0.1 \mathrm{~mol} \%)$ & 1.5 & Air & - \\
\hline 3 & TPP (1 mol\%) & 1.5 & Air & 97 \\
\hline 4 & ТРP $(0.1 \mathrm{~mol} \%)$ & 1.5 & Air & Quant. \\
\hline 5 & TPP (0.01 mol\%) & 3 & Air & Quant. \\
\hline 6 & TPP (0.01 mol\%) & 3 & $\mathrm{~N}_{2}$ & 33 \\
\hline 7 & TPP (0.01 mol\%) & 3 & Dark, air & 6 \\
\hline 8 & $\mathrm{RB}(1 \mathrm{~mol} \%)$ & 1.5 & Air & n.r. \\
\hline 9 & MB (1 mol\%) & 1.5 & Air & 19 \\
\hline 10 & EosinY (1 mol\%) & 1.5 & Air & 3 \\
\hline 11 & None & 1.5 & Air & n.r. \\
\hline
\end{tabular}

${ }^{a}$ Conditions: dimesityltelluride $(0.1 \mathrm{mmol})$, TFA $(0.22 \mathrm{mmol})$, sensitizer, and $\mathrm{CH}_{2} \mathrm{Cl}_{2}(10 \mathrm{~mL})$ under aerobic conditions at room temperature. ${ }^{b}$ TPP, $\mathrm{RB}$ and $\mathrm{MB}$ denote tetraphenylporphyrin, rose bengal and methylene blue, respectively. ${ }^{c}$ Determined using ${ }^{1} \mathrm{H}$ NMR spectroscopy. 


\section{Synthesis}

Initially, we investigated the transformation of a diaryltelluride into a diaryltellurium dicarboxylate under a variety of reaction conditions. For that purpose, a solution of dimesityltelluride, 2.2 equivalents of trifluoroacetic acid (TFA), and a photosensitizer [fullerene-C60, tetraphenylporphyrin (TPP), methylene blue (MB), rose bengal ( $\mathrm{RB})$, or eosin $\mathrm{Y}$ ] was stirred at room temperature, whilst being exposed to irradiation from a white LED. The product yields are summarized in Table 1 . We found that fullerene-C60 and TPP were effective photosensitizers for this reaction, while $\mathrm{RB}, \mathrm{MB}$, and eosin $\mathrm{Y}$ (Table 1, entries 8-10) were ineffective. Furthermore, the reaction did not proceed in the dark or under a nitrogen atmosphere (Table 1, entries 6, 7). In other words, this reaction requires oxygen from the surrounding air and light for optimal results. The best results for this model reaction were obtained using TPP as the photosensitizer with LED irradiation in an open flask (Table 1, entry $5)$.

Next, we used the optimal reaction conditions to investigate the substrate scope of the reaction (Table 2). When diphenyltelluride, dimesityl telluride, or bis(4-methoxyphenyl) telluride ware reacted with acetic acid, the corresponding diaryltellurium dicarboxylates (1a, $\mathbf{1 b}$, and $\mathbf{1 d})$ were obtained in good yields. However, bis(4-fluorophenyl) telluride was not reactive under these conditions and the reaction at room temperature yielded many by-products. However, when this reaction was performed at $0{ }^{\circ} \mathrm{C}$, the target product (1c) was obtained. Next, the reactions of various carboxylic acids with diphenyltelluride or dimesityl telluride were investigated. In all cases, the reaction proceeded to give the expected diaryltellurium dicarboxylates in good to excellent yields (2a-6b).

The reaction is thought to produce the diaryltellurium dicarboxylates after the generation of the telluroxides via photooxidation (Scheme 1). First, triplet oxygen is converted to singlet oxygen using the photosensitizer in the presence of light. Singlet-oxygen oxidation of the telluride then gives the corresponding telluroxide, a reaction that has already been reported. ${ }^{10}$ The telluroxide then reacts with the carboxylic acid to produce the corresponding tellurium dicarboxylate and water. To investigate this proposed mechanism further, we reacted diphenyltelluroxide with 2 equivalents of acetic acid under mild conditions, which furnished the tellurium dicarboxylate diphenyl-tellanediyl diacetate in quantitative yield.

Table 2 Substrate scope of the reaction ${ }^{c}$

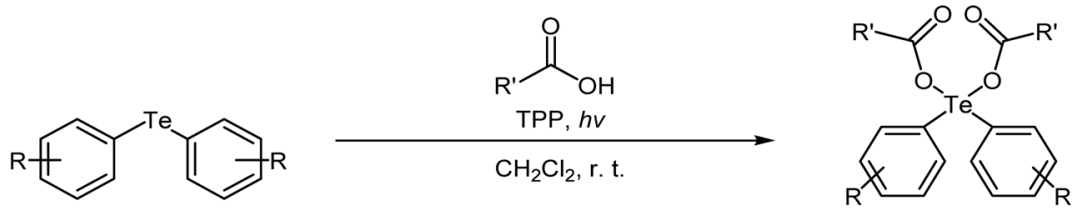

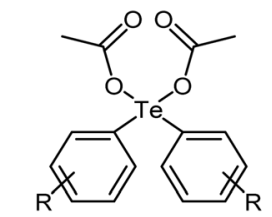

$\mathrm{R}=\mathrm{H}$ :

$\mathrm{R}=2,4,6-\mathrm{Me}: \mathbf{1 b}$, quant

$\mathrm{R}=4-\mathrm{F}$ :

$\mathrm{R}=4-\mathrm{OMe}: \quad 1 \mathrm{~d}, \quad 82 \%$

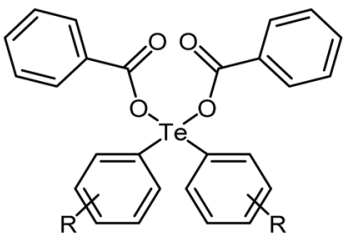

$\mathrm{R}=\mathrm{H}: \quad \mathbf{4 a}, \quad 61 \%$

$\mathrm{R}=2,4,6-\mathrm{Me}: \mathbf{4 b}, \quad 69 \%$

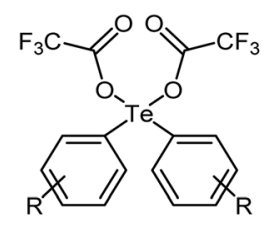

$\mathrm{R}=\mathrm{H}: \quad \mathbf{2 a}, \quad 82 \%$

$\mathrm{R}=2$, 4, 6-Me: $\mathbf{2 b}$, quant

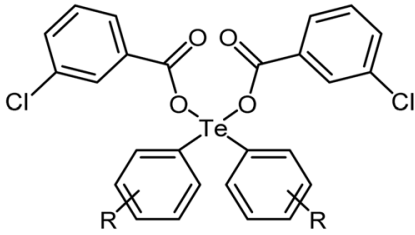

$\mathrm{R}=\mathrm{H}: \quad \mathbf{5 a}, \quad 95 \%$

$\mathrm{R}=\mathbf{2}, \mathbf{4}, 6-\mathrm{Me}: \mathbf{5 b}, \quad 96 \%$

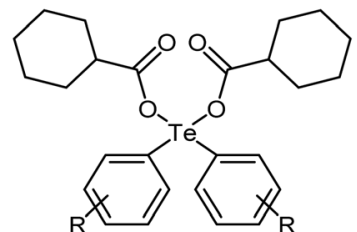

$\mathrm{R}=\mathrm{H}: \quad 3 \mathbf{a}$, quant.

$R=2$, 4, 6-Me: $\mathbf{3 b}$, quant.

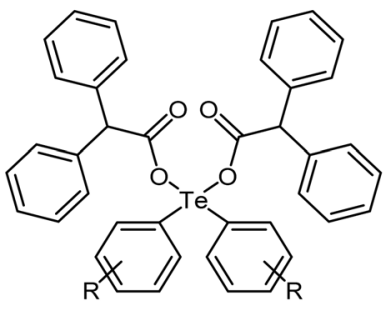

$\mathrm{R}=\mathrm{H}: \quad 6 \mathrm{a}, \quad 84 \%{ }^{\mathrm{b}}$

$\mathrm{R}=2,4,6-\mathrm{Me}: \mathbf{6 b}, \quad 69 \%$ ${ }^{a}$ Run at $0{ }^{\circ} \mathrm{C} .{ }^{b} 0.25 \mathrm{mmol}$ of carboxylic acid was used. ${ }^{c}$ Conditions: diaryltelluride $(0.1 \mathrm{mmol})$, carboxylic acid $(0.22 \mathrm{mmol}), \mathrm{TPP}(0.01 \mathrm{~mol} \%)$, and
$\mathrm{CH}_{2} \mathrm{Cl}_{2}(10 \mathrm{~mL})$ under aerobic conditions at room temperature. 


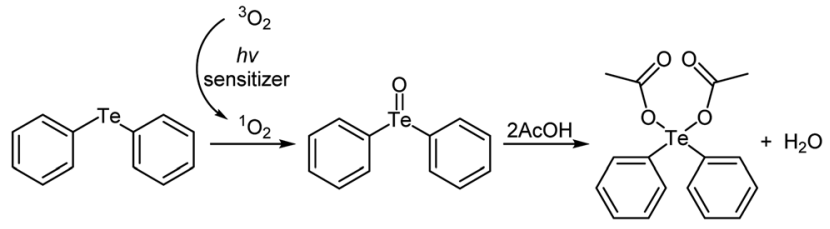

Scheme 1 Multistep synthesis of diaryltellurium dicarboxilates

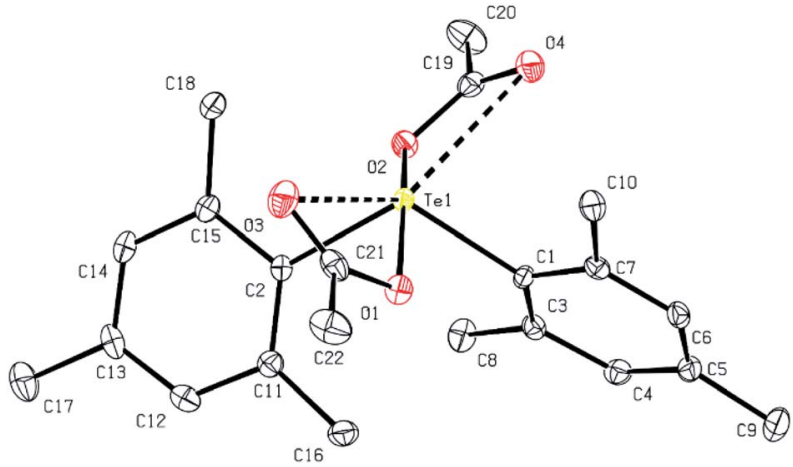

Fig. 1 Structure of bis(2,4,6-trimethylphenyl) tellurium diacetate $1 \mathrm{~b}$ thermal ellipsoids at $60 \%$ probability level. Selected bond distances $(\AA)$ and angles $\left({ }^{\circ}\right)$ : Te1-C1, 2.133(2); Te1-C2, 2.1368(19); Te1-O1,

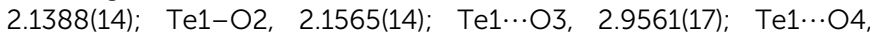
2.9951(15); O1-Te1-O2, 164.43(6); C1-Te1-C2, 111.17(8); C1-Te1O1, 84.15(7); C2-Te1-O1, 86.46(7); C1-Te1-O2, 88.19(7); C2-Te1-

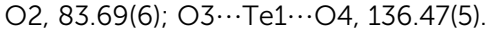

\section{Single-crystal-X-ray diffraction analysis}

Colorless crystals of $\mathbf{1 a - 1 d , 2 b}$ and $\mathbf{6 a}$, suitable for single-crystal $\mathrm{X}$-ray diffraction analysis, were collected following the slow diffusion of $n$-hexane into chloroform solutions of 1a-1d, $\mathbf{2 b}$ and $\mathbf{6 a}$ at room temperature. Some of the structures of these diaryl tellurium dicarboxylates were determined using X-ray crystallographic analysis. The molecular structure of bis(2,4,6trimethylphenyl) tellurium diacetate $\mathbf{1 b}$ is shown in Fig. $\mathbf{1 .}$ Selected bond distances and angles for $\mathbf{1 b}$ are summarized in the caption of Fig. 1. The acetoxy groups are located in apical positions and the aryl groups are located at equatorial positions. The presence of the lone pair at the third equatorial position is inferred by the reduction of the equatorial $\mathrm{C}-\mathrm{Te}-\mathrm{C}$ and apical $\mathrm{O}-\mathrm{Te}-\mathrm{O}$ bond angles which are $111.17(8)^{\circ}$ and $164.43(6)^{\circ}$, respectively. The observed Te-O (2.1388(14),
Table 4 Oxidation of benzoin to benzil using diaryltellurium dicarboxylates ${ }^{a}$

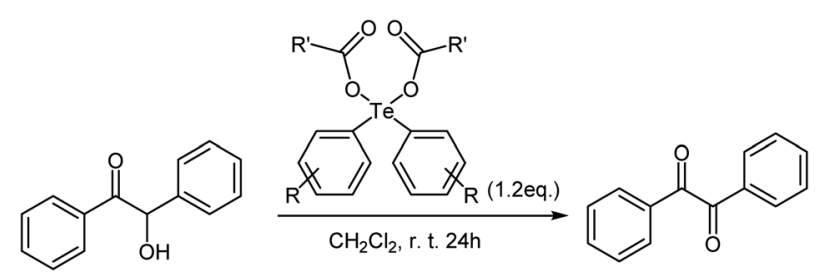

\begin{tabular}{lll}
\hline Entry & Diaryltellurium dicarboxylates & Yield $^{b}(\%)$ \\
\hline 1 & 1a & 19 \\
2 & 1b & 9 \\
3 & 1c & 21 \\
4 & 1d & 8 \\
5 & 2a & 97 \\
6 & 2b & 99
\end{tabular}

${ }^{a}$ Conditions: benzoin $(0.25 \mathrm{mmol})$ diaryltellurium dicarboxylates $(0.3$ $\mathrm{mmol})$ and $\mathrm{CH}_{2} \mathrm{Cl}_{2}(3 \mathrm{~mL})$, under aerobic conditions at room temperature for $24 .{ }^{b}$ Isolated yield.

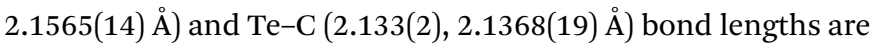
in good agreement with those of analogous diaryl tellurium dicarboxylates. ${ }^{11}$ The selected bond lengths and bond angles for $\mathbf{1 a}-\mathbf{1 b}, \mathbf{2 b}$ and $\mathbf{6 a}$ are given in Table 3 . The central Te core of all four structures is very similar as are the structures of all the diaryltellurium dicarboxylates shown in this article. The major difference between these compounds is the bond angle between the substituents located in the equatorial position. The compounds with bulky aryl groups (1b and $\mathbf{2 b}$ : Mes) have a slightly wider C1-Te-C2 angle $\left(\mathbf{1 b}: 111.2^{\circ} ; \mathbf{2 b}\right.$ : $\left.111.4^{\circ}\right)$ than the other compounds. On the other hand, differences in the other aryl groups have little effect on the bond angle between the substituents located in the equatorial position.

\section{Applications in oxidation reactions}

As a exemplary applications for the obtained diaryltellurium dicarboxylates, we examined the oxidation of benzoin to benzil. The oxidative transformation of benzoin to benzil moieties has been accomplished using a wide variety of reagents or catalysts and different reaction procedures. Several reagents have been used for this transformation, including nitric acid, bismuth(III) nitrate-copper(II) acetate ${ }^{12}$ and $\mathrm{Y}(\mathrm{III})$ nitrate bismuth(III) nitrate-

Table 3 Comparison of the relevant Te bond lengths and angle

\begin{tabular}{|c|c|c|c|c|c|c|c|}
\hline Bond length $(\AA)$ or angle $\left(^{\circ}\right)$ & $1 \mathbf{a}$ & $1 \mathbf{b}$ & $1 c$ & 1d & 1d & $2 \mathbf{b}$ & $6 \mathbf{a}$ \\
\hline Te-O1 length (shoter) & 2.164 & 2.139 & 2.152 & 2.143 & 2.168 & 2.154 & 2.158 \\
\hline Te-O2 length (longer) & 2.164 & 2.157 & 2.152 & 2.177 & 2.173 & 2.174 & 2.158 \\
\hline Te-C1 length (shoter) & 2.124 & 2.133 & 2.098 & 2.093 & 2.080 & 2.125 & 2.097 \\
\hline Te-C2 length (longer) & 2.124 & 2.137 & 2.098 & 2.095 & 2.106 & 2.126 & 2.097 \\
\hline O1-Te-O2 angle & 167.0 & 164.4 & 168.0 & 164.1 & 169.0 & 165.9 & 163.5 \\
\hline C1-Te-C2 angle & 93.6 & 111.2 & 95.7 & 99.4 & 99.9 & 111.4 & 100.2 \\
\hline
\end{tabular}


Table 5 Substrate scope of the oxidation reaction using diaryItellurium dicarboxylates $^{a}$

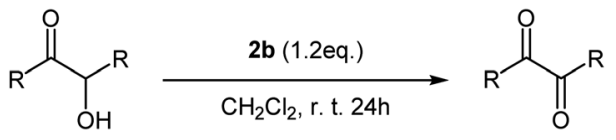

\begin{tabular}{lll}
\hline Entry & $\mathrm{R}$ & Yield $^{b}(\%)$ \\
\hline 1 & Phenyl & 97 \\
2 & n-Butyl & 96 \\
3 & 4-Methoxyphenyl & Quant. \\
4 & 4-Methylphenyl & 91 \\
5 & 2-Furan & 98
\end{tabular}

${ }^{a}$ Conditions: benzoin $(0.25 \mathrm{mmol})$ diaryltellurium dicarboxylates $(0.3$ mmol) and $\mathrm{CH}_{2} \mathrm{Cl}_{2}(3 \mathrm{~mL})$, under aerobic conditions at room temperature for $24 .{ }^{b}$ Isolated yield.

copper(II) acetate. ${ }^{13}$ The practical utility of these reagents is limited by the requirement for stoichiometric amounts of corrosive acids or high reaction temperatures. On the other hand, reports on oxidation reactions using diaryltellurium dicarboxylates remain elusive.

We investigated a model oxidation reaction of benzoin to benzil using various diaryltellurium dicarboxylates. For that purpose, $\mathrm{CH}_{2} \mathrm{Cl}_{2}$ solutions of benzoin and diaryltellurium dicarboxylates were stirred for $24 \mathrm{~h}$ in an open flask at room temperature. After the reaction, benzil was isolated by column chromatography; yields are summarized in Table 4 . The activity of the diaryltellurium dicarboxylates with trifluoroacetates (2a and $\mathbf{2 b}$ ) was higher than that of the other diaryltellurium dicarboxylates (Table 4, entries 5 and 6).

Subsequently, we investigated the scope of applicable benzoin derivatives under the previously established optimal reaction conditions and the results are summarized in Table 4 . Overall, the reactions proceeded rapidly and furnished the expected oxide in good to excellent yield (Table 5, entries 1-5). This oxidation reaction, based on diaryltellurium dicarboxylates, proceeds under mild conditions and does not require the use of acids or bases.

\section{Conclusions}

We have developed a one-pot synthesis of a series of diaryl tellurium dicarboxylates under safe and mild reaction conditions using atmospheric oxygen and inexpensive carboxylic acids. Furthermore, we have structurally characterized multiple diaryl tellurium dicarboxylates, and we discovered that these diaryltellurium dicaboxylates can be used to oxidaze benzoin under mild reaction conditions. The findings presented herein can be expected to lead to new research areas that employ diaryl tellurium dicarboxylates in the future.

\section{Conflicts of interest}

There are no conflicts to declare.

\section{Notes and references}

1 S. Koguchi, Y. Shibuya, Y. Igarashi and H. Takemura, Synlett, 2019, 30, 99.

2 M. Oba, K. Nishiyama, S. Koguchi, S. Shimada and W. Ando, Organometallics, 2013, 32, 6620.

3 A. Mihoya, Y. Shibuya, A. Ito, A. Toyoda, M. Oba and S. Koguchi, Synlett, 2020, 31, 2043.

4 A. Mihoya, S. Koguchi, Y. Shibuya, M. Mimura and M. Oba, Catalysts, 2020, 10, 398.

5 Z. Liu and Z. Chen, Heteroat. Chem., 1992, 3, 559.

6 T. Kataoka and S. Watanabe, Sci. Synth., 2007, 31, 1159.

7 V. Chandrasekhar, A. Kumar, M. D. Pandey and R. K. Metre, Polyhedron, 2013, 52, 1362.

8 V. Chandrasekhar and R. Thirumoorthi, Eur. J. Inorg. Chem., 2008, 4578.

9 K. Kobayashi, H. Izawa, K. Yamaguchi, E. Hornc and N. Furukawa, Chem. Commun., 2001, 1428.

10 M. Oba, M. Endo, K. Nishiyama, A. Ouchi and W. Ando, Chem. Commun., 2004, 1672; M. Oba, Y. Okada, K. Nishiyama, S. Shimada and W. Ando, Chem. Commun., 2008, 537; M. Oba, Y. Okada, K. Nishiyama and W. Ando, Org. Lett., 2009, 11, 1879; Y. Okada, M. Oba, A. Arai, K. Tanaka, K. Nishiyama and W. Ando, Inorg. Chem., 2010, 49, 383.

11 V. Chandrasekhar and A. Kumar, J. Organomet. Chem., 2009, 694, 2628.

12 S. Tymonko, B. Nattier and R. Mohan, Tetrahedron Lett., 1999, 40, 765.

13 A. McKillop, B. Swann, M. Ford and E. Taylor, J. Am. Chem. Soc., 1973, 95, 3641. 